\title{
In Memoriam: Professor Akio Kanazawa (1930-2009)
}

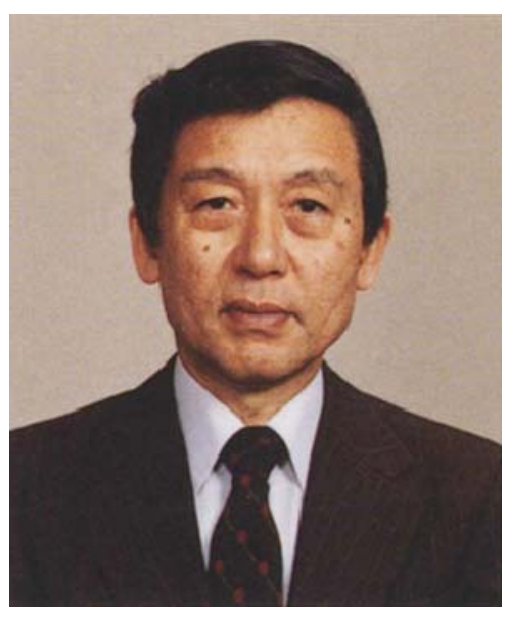

Professor Akio Kanazawa, an Honorary Member of the Japanese Society of Fisheries Science, passed away at the age of 78 at his home in Kagoshima, Japan on 14 February 2009.

Professor Kanazawa was born in Kagoshima on 19 April 1930. Following completion of his studies, he was appointed Research Assistant (currently termed Assistant Professor) at the Faculty of Fisheries, Kagoshima University in 1952. In 1965 he was promoted to Associate Professor, then to Full Professor in 1981. Following his retirement in 1996, he remained at the Faculty of Fisheries as Professor Emeritus of Kagoshima University, a recognition of his extraordinary contribution to the academic development of the university. Professsor Kanazawa was active in many field of fishery research and published many interesting findings during his academic career. He also supervised and trained a large number of Japanese and international students who went on to have active roles not only in fisheries and associated food processing industries but also in a wide range of businesses.
Professor Kanazawa's major area of research was the determination of the nutritional requirements of kuruma shrimp and other aquatic animals and the development of formulated feeds for aquatic animals. He was particularly successful in developing microparticulate diets for larval aquatic animals. These findings facilitated the development of seed production technology, progress in studies of aquatic animal nutrition, and associated industrial developments. Professor Kanazawa published many scientific papers in Fisheries Science and Suisan Gakkaishi, which he also presented in the Symposium of the Japanese Society of Fisheries Science. These symposium contents have been published in various series of Fisheries Science, such as "Aquaculture of Crustacean", "Hormone of Aquatic Animals", "Evaluation of Fisheries Products", "Control of Maturation and Spawning in Aquatic Animals", "Fish Nutrition and Diets", "Functional Substances of Marine Origin", "Chemical Stimulants for Feeding Behavior of Fish and Shellfish", "Fisheries Lipids" and many others. He served on a number of committees and boards, including the committee of society award, symposium committee, editorial board of Fisheries Science, and the local committee board. His publications on "Study of Sterols in Marine Invertebrates" in 1972 and "Biochemical and Nutritional Chemical Studies on Crustaceans" in 1994 were recognized with awards by the Japanese Society of Fisheries Science. Professor Kanazawa's devotion and personal contribution to the Society was great and unforgettable.

We would therefore like to express our deep condolences to the family and friends of Prof. Akio Kanazawa and also express our gratitude for his achievements in research and education.

Shunsuke Koshio

Professor, Faculty of Fisheries, Kagoshima University 